\title{
A study of adequacy of informed consent before caesarean section in a tertiary care hospital
}

\author{
Nishu Bhushan, Aakriti Manhas* \\ Department of Obstetrics and Gynaecology, SMGS Hospital, Govt. Medical College, Jammu, J\&K, India
}

Received: 22 November 2021

Revised: 18 December 2021

Accepted: 23 December 2021

\section{*Correspondence:}

Dr. Aakriti Manhas,

E-mail: aakritimanhas660@gmail.com

Copyright: $\odot$ the author(s), publisher and licensee Medip Academy. This is an open-access article distributed under the terms of the Creative Commons Attribution Non-Commercial License, which permits unrestricted non-commercial use, distribution, and reproduction in any medium, provided the original work is properly cited.

\begin{abstract}
Background: Informed consent is an ethical and legal requirement and is practiced before all the surgical procedures. Caesarean section is the commonest obstetric surgery so, this study was aimed to assess the adequacy of informed consent in patients who underwent caesarean section at SMGS Hospital, GMC, Jammu.

Methods: A cross-sectional study was done. A total of 230 patients were included in the study. A pre-tested and prevalidated questionnaire was used for the study. The data were expressed as percentage of proportion.

Results: 230 patients participated in the study. About $96.95 \%$ patients knew the name of the procedure. $91.73 \%$ patients were informed about the indication of the surgery. $95.21 \%$ of the patients were aware about the benefits of surgery and about $93.41 \%$ of the patients were knowing risks of surgery. About $83.04 \%$ patients were informed about the procedure of the surgery. About $94.78 \%$ and $94.34 \%$ of the patients were aware about the need for the blood transfusion and future pregnancy options. Only about $4.35 \%$ of the patients were informed about the requirement and type of anaesthesia. $22.18 \%$ of the patients knew about the choice for alternate procedure and merely $2.18 \%$ of the patients were informed about the right to refuse the procedure.

Conclusions: It was found that majority of the patients were well informed about the procedure and the related consequences. Still we can improve some elements of the consent process which can be done by proper awareness and training of health care professionals.
\end{abstract}

Keywords: Informed consent, Caesarean section, Questionnaire, Knowledge

\section{INTRODUCTION}

Informed consent is defined as permission granted in full knowledge of the possible consequences, typically that which is given by a patient to a doctor for treatment with knowledge of the possible risks and benefits. Informed consent provider educates a patient about the risks, benefits and alternatives of a given procedure or intervention. ${ }^{1}$ In the case of caesarean section, informed consent must include name, nature, proposed benefits of the procedure, alternative options, implications on the future reproductive health and anesthetic options. ${ }^{2}$ The consent helps the patient to take a decision whether to accept or reject any treatment and helps in building a relationship between the doctor and the patient. Caesarean delivery is one of the most frequently performed surgeries in women. With improving basic health care facilities and greater percentage of institutional deliveries as envisioned by most of the health care programmes, a proportionate increase in diagnosis of complicated cases has occurred. Better diagnosis and early referral have simultaneously increased the rate of caesarean deliveries at tertiary care hospitals of India. The World Health Organization (WHO) has projected a target that caesarean section should be upto $15 \%$. $^{3}$ In early times, all the patients who had undergone caesarean section were subjected to elective caesarean 
section for their subsequent deliveries. ${ }^{4,5}$ But in recent times, the practice has changed and vaginal births after caesarean section has become an acceptable alternative. ${ }^{6}$ Some factors like availability of trained surgeon, blood transfusion facilities and safe anaesthetic facilities affect the decision of opting for caesarean section. ${ }^{7,8}$ Many studies have proved that caesarean section has greater morbidity and mortality than normal vaginal delivery. Even if most of the caesarean sections are done in good faith, it does not escape the preview of consumer awareness and protection. It is well implicit that informed consent is required for an elective or emergency caesarean section. It is both an ethical and legal requirement. Because of increasing knowledge about ethics and rights, issues on consent process have become one of the frequent grounds for litigation and malpractice cases. As the rate of caesarean section is increasing in tertiary care hospitals in India, there are concerns regarding the active participation of patients in decision making of the choice of operative interventions. Therefore, this study was done at a tertiary level government institution to understand the level of awareness of the patients undergoing caesarean section regarding the indication, procedure and various other aspects which are essential for the patient or attendants to know before giving an informed consent. This study was carried out with an aim to provide insight into adequacy of the consenting process before caesarean section. The objective of the study was to assess the proportion of the patients receiving adequate informed consent before caesarean section.

\section{METHODS}

This was a cross-sectional study conducted in the department of Obstetrics and Gynecology, SMGS Hospital, Government Medical College, Jammu of the Union Territory of Jammu and Kashmir from November 2020 to April 2021. The study population was chosen from patients who underwent caesarean section at SMGS Hospital, GMC Jammu. The patients who were more than 18 years of age and underwent an elective/emergency caesarean section and had given consent for participation in the study were included in the study. The procedures which were planned for and performed before labor were defined as elective caesarean sections and the surgeries which were unplanned and were performed during labor and after complications arose were defined as emergency caesarean sections. Total 230 women participated in the study. The study tool, a pre-tested questionnaire of some other study was adopted and modified to some extent as per the local needs of the study. ${ }^{9}$ The questionnaire had two parts. The first part described the demographic profile and the second part contained questions regarding the procedure performed and other aspects of informed consent. In the second part of the questionnaire, the responses were recorded in five point likert scale. The responses for strongly agree and agree were considered as adequate and responses for neutral, disagree and strongly disagree were considered as inadequate. The data were collected and entered into the microsoft excel sheet and the data base was created which was analysed by the Statistical package for social sciences (SPSS) software version 19.0. The data were expressed in percentage of proportion.

\section{RESULTS}

Total 230 women participated in the study. Among the participants $168(73.04 \%)$ patients were in the age group of 21-30 years.

Table 1: Demographic distribution of the patients.

\begin{tabular}{|ll|}
\hline Age (years) & $\begin{array}{l}\text { Number of } \\
\text { participants }\end{array}$ \\
\hline $18-20$ & $14(6.08 \%)$ \\
\hline $21-30$ & $168(73.04 \%)$ \\
\hline $31-40$ & $48(20.86 \%)$ \\
\hline Education level & $20(8.69 \%)$ \\
\hline Illiterate & $70(30.43 \%)$ \\
\hline Upto middle & $50(21.73 \%)$ \\
\hline Upto matric & $53(23.04 \%)$ \\
\hline Upto 10+2 & $30(13.04 \%)$ \\
\hline Upto graduation & $7(3.04 \%)$ \\
\hline Upto post-graduation & \\
\hline No. of days since C section & $153(66.52 \%)$ \\
\hline $0-3$ days & $50(21.73 \%)$ \\
\hline 4-6 days & $27(11.73 \%)$ \\
\hline Above 6 days & \\
\hline Place of residence & $149(64.78 \%)$ \\
\hline Rural & $81(35.21 \%)$ \\
\hline Urban & $48(20.86 \%)$ \\
\hline Type of procedure & $182(79.13 \%)$ \\
\hline Elective & \\
\hline Emergency & \\
\hline
\end{tabular}

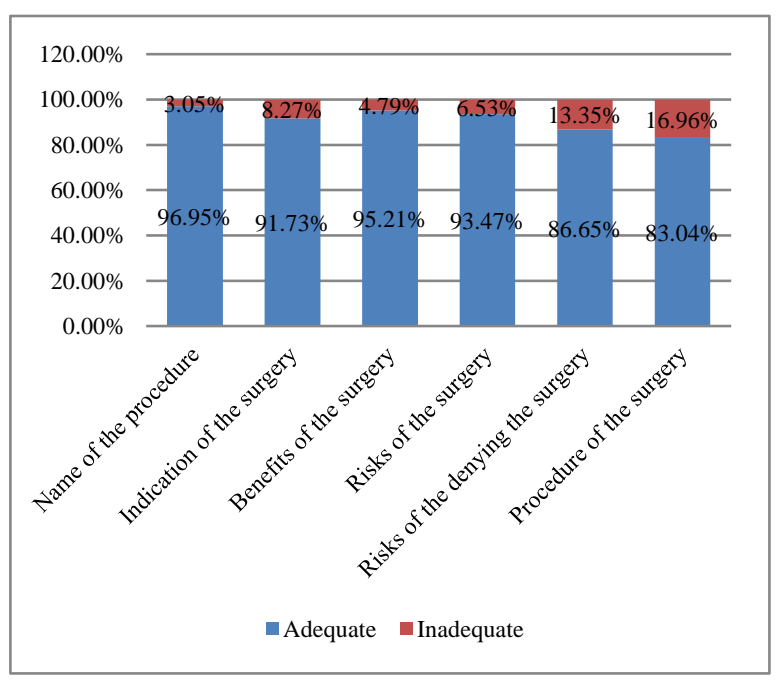

Figure 1: Responses of the patients to the questionnaire (data are expressed as percentages).

Only $48(20.86 \%)$ patients were in the age group of above 30 years. It was observed that most of the patients were educated upto middle standard $(30.43 \%)$ followed by 
$23.04 \%$ of the patients who were educated upto12th standard. Majority of the patients $(64.78 \%)$ belonged to rural areas and $35.21 \%$ belonged to urban areas. $79.13 \%$ of the patients underwent emergency while $20.86 \%$ of the patients underwent elective caesarean section. (Table 1)

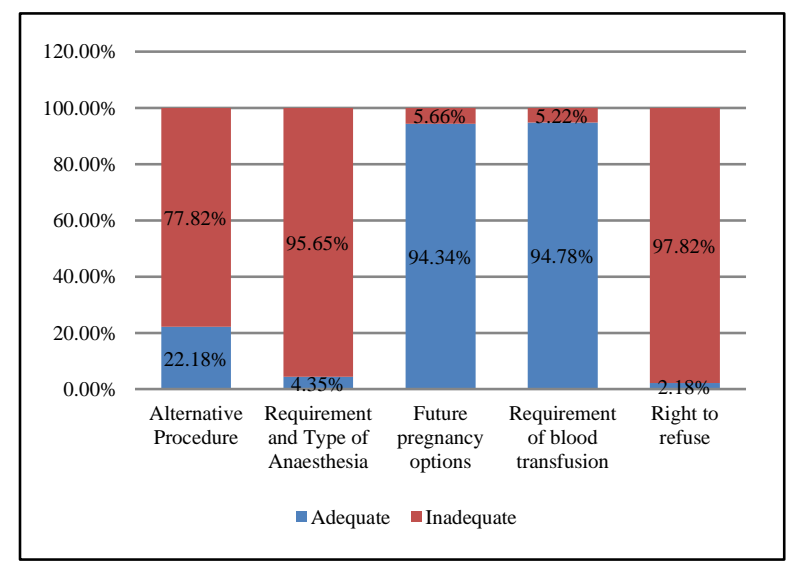

Figure 2: Responses of the patients to the questionnaire (data are expressed as percentage).

In the second part, there were questions to elicit responses from the participants to find their knowledge. The responses were categorized into two categories; adequate and inadequate. Most of the patients were informed regarding the name, nature, indications and risks and benefits of the surgery adequately (Figure 1). On the other hand, knowledge of the participants was not adequate regarding some aspects of informed consent like availability of alternative procedure, requirement and type of anaesthesia and right to refuse the procedure (Figure 2).

\section{DISCUSSION}

The healthcare facilities and coverage have received a boost with proper and strict implementation of various schemes like JSSK (Janani Shishu Surkasha Karyakram), National Ambulance Services and Mother-Child tracking system under the National Health Mission. As a result of these schemes, there is significant rise in the institutional deliveries due to increased awareness about the health facilities as well as strengthening of primary health centers with ease of referral and better transport facilities. As there is an increased load of deliveries in the institutions, the responsibility lies on the healthcare providers to improve and maintain the quality of healthcare.

Pre-operative and post-operative patient counselling is an important and integral part in the maternal care. There is an increase in medico-legal problems due to wrong or inadequate information provided to the patients or relatives. ${ }^{10}$ In most of the emergency caesarean sections, the informed consent forms are signed by the relatives instead of the patient. The results of our study indicate that majority of the patients and their relatives were informed adequately before caesarean section. In our study, it was observed that most of the patients belonged to 21-30 years age group (73.04\%), 64.787\% belonged to rural areas, $30.43 \%$ of the patients had studied till middle standard followed by $23.04 \%$ who had studied upto 12 th standard. $66.52 \%$ patients were those who had their post-operative day 0 to post-operative day 3 of hospital stay, followed by $21.73 \%$ having history of LSCS 4-6 days back and $11.73 \%$ had LSCS more than 6 days back. Most of the patients $(79.13 \%)$ had emergency LSCS and $20.86 \%$ of the patients had elective LSCS. As observed in our study, $96.95 \%$ of the patients were able to name the procedure that they underwent and $91.73 \%$ of the patients were able to tell the indications of the surgery. About $95.21 \%$ and $93.47 \%$ of the patients were able to understand the benefits and risks of surgery respectively. $83.04 \%$ patients had knowledge about the procedure of surgery. This high percentage of adequacy regarding the informed consent process in our study indicates that the patients were literate to understand the process and the healthcare professionals were able to provide a better understanding of the informed consent process before the caesarean section. Our findings are comparable with the findings in the study done by Latika et al which shows that about $93 \%$ of the patients were adequately informed about the name of the procedure, $98 \%$ of the patients had adequate knowledge about the nature of the procedure and $85 \%$ of the patients were aware about the indications of the procedure. ${ }^{2}$ Another study has shown that $71 \%$ of the patients had knowledge about the indications of the caesarean section but only $25 \%$ of the patients were able to explain the procedure and complications. ${ }^{10}$ It indicates that there is lack of information during the consent process. Many a times, it is seen that patients are explained about the indications while nature of the procedure, risks and benefits of the procedure are not communicated properly which can lead to legal problems if the patient develops any complication intraoperatively or post-operatively. In our study, it was seen that $95.65 \%$ of the patients were not explained about the requirement and type of anaesthesia during the procedure. Latika et al in their study also found that $80 \%$ of the patients were not informed about the type of anaesthesia and $87 \%$ of the patient were not given the chance to choose the type of anaesthesia. ${ }^{2}$ Where possible, the women must be made aware of the form of anaesthesia planned and should be given an opportunity to discuss in detail with the anaesthetist before surgery. ${ }^{11}$ In our study, only $22.18 \%$ of the patients were informed about the availability of alternate procedure. In another study, it was observed that only $26.3 \%$ of the patients were informed about the alternative procedure. ${ }^{12}$ Only $2.18 \%$ of the patients in our study were knowing the right to refuse the procedure. But a study done in Zambia has shown that about $50 \%$ of the patients were informed about the rights to decline the interventions. ${ }^{9}$ A well informed competent woman may choose no treatment option; that is, she may refuse caesarean section, even when this may be detrimental to her own health or the well-being of her own fetus. ${ }^{12}$ Most of the patients in our study were adequately informed about the options for future pregnancy and majority of them $(77.82 \%)$ preferred to go for vaginal delivery than caesarean section. But the risk involved in future 
pregnancies like risk of uterine rupture (2-7/1000 women), ante-partum still-birth (1-4/1000 women) and placenta previa and placenta accreta (4-8/1000 women) should be well informed. ${ }^{11}$

So, in our study, we observed that most of the aspects of informed consent process are carried out adequately but still some aspects are there which need to be taken care of. Factors like age of the patients, education status, gestational age of the patient at the time of delivery, type of caesarean section whether emergency or elective, the counselling and explanation provided by the healthcare professional are important to maintain the quality of consent process. The patient education and proper counselling regarding the peri-operative and postoperative complications are indispensable. Many a times, emergent indications need immediate action, which might not provide enough time for proper counselling of the patient or her relatives. Regarding the awareness about the risks and complications of caesarean section, the patients and relatives should be counselled during ante-natal visits. If the obstetrician foresee any chance of caesarean section during the ante-natal check-up near the term, he/she should start counselleing. This will help the patients or relatives to participate in taking a decision during the consent process even during an emergency situation.

Our study has few limitations as it highlights some but not all the variables that could affect the patient's attitude towards informed consent. A larger multi-centre study is required to validate the findings.

\section{CONCLUSION}

Majority of the caesarean sections were performed for some emergency indications. It was seen that majority of the patients were well informed about the procedure and the related consequences but still few aspects were not covered in the consent. Thus, it can be concluded that process of informed consent can be improved by making proper proforma/checklist and training of the healthcare professionals who are involved in consent process. Similar studies should be carried out at tertiary care hospitals at regular intervals. The results of such studies will help to improve further on the informed consent process and maintain a good doctor-patient relationship with less medico-legal litigations.

Funding: No funding sources

Conflict of interest: None declared
Ethical approval: The study was approved by the Institutional Ethics Committee

\section{REFERENCES}

1. Shah P, Thornton I, Hipskind JE. Informed consent. Stat Pearls. 2020;11:20-4.

2. Latika L, Nanda S, Duhan N, Malik R. Study of adequacy of informed consent in caesarean section in a tertiary care, teaching and research institute of Northern India. Int $\mathbf{J}$ Reprod Contracept Obstet Gynecol. 2015;4:780-4.

3. World Health Organization. Appropriate technology for birth. Lancet. 1985;326(8452):436-7.

4. Roberts LJ. Elective section after two sectionswhere's the evidence. Br J Obstet Gynaecol. 1991;98(12):1192-202.

5. Flamm BL. Vaginal Birth after caesarean (VBAC). Best Pract Res Clin Obstet Gynaecol. 2001;15(1):8192.

6. NHS guidelines on caesarian section. London (UK): National Institute of Clinical Excellence (NICE). 2004.

7. Lawson BL, Harrison KA, Bergstrom S. Maternity care in developing countries. Lawson BL, Harrison KA, Bergstrom S, editors. London: RCOG Press. 2001.

8. World Health Organization. Managing Complications in pregnancy and child birth. In: Integrated Management of Pregnancy and Childbirth (IMPAC). Geneva: WHO. 2003.

9. David C. Lubansa (UNZA). A study of adequacy of informed consent for caesarean section at the university teaching Hospital, Lusaka, Zambia. School of Medicine. 2010;1-38.

10. Kirane AG, Gaikwad NB, Bhingare PE, Mule VD. Informed" Consent: An audit of informed consent of cesarean section evaluating patient education and awareness. J Obstet Gynaecol India. 2015;65(6):3825 .

11. Royal college of obstetricians and gynecologists. Caesarean section. In: Consent Advice 7. 2nd ed. UK: RCOG. 2009.

12. Ngim NE, Ndifon WO, Umoh MS, Ogunkeyede A. Informed consent for surgery in Nigeria: Is the practice adequate? Glob J Med Sci. 2009;7(1-2):3942.

Cite this article as: Bhushan N, Manhas A. A study of adequacy of informed consent before caesarean section in a tertiary care hospital. Int J Reprod Contracept Obstet Gynecol 2022;11:445-8. 